\title{
I need Spain. Análisis pragmático de la campaña de promoción turística 2010
}

\author{
Laura Mariottini ${ }^{\mathrm{i}}$
}

Sapienza Università di Roma (Italia)

Resumen: En el presente trabajo se analiza la última campaña de promoción turística lanzada por el Gobierno español el 4 de marzo de 2010, I need Spain. En concreto, se describirán las estrategias pragmáticas empleadas para la comunicación y los efectos que tienen en los destinatarios.

El marco teórico se compone de la pragmática (Escandell, 1994; Sbisà, 1994; Orletti, 1994), de los trabajos que estudian la interacción entre lo visual y lo verbal en los anuncios de publicidad (Lombardi Vallauri, 2009; Held, 2004, 2005, 2007) y de la literatura sobre lengua y comunicación del turismo (entre otros, Santulli, Antelmi y Held, 2007; Calvi y Mapelli, 2011).

Palabras clave: I need Spain, visual-verbal, implicaturas conversacionales, lengua del turismo.

Title: I need Spain. A pragmatic analysis of the 2010 tourism promotion campaign.

Abstract: This paper analyzes the latest tourism promotion campaign launched by the Spanish Government on March 4, 2010, I need Spain. Specifi cally, it focuses on describing the pragmatic strategies used for communication and the effects they have on the recipients. The theoretical framework consists of pragmatics (Escandell, 1994; Sbisà, 1994; Orletti, 1994), studies regarding the interaction between visual and verbal information in advertisements (Lombardi Vallauri, 2009; Held, 2004, 2005, 2007) and bibliography about language and communication of tourism (among others, Santulli, Antelmi and Held, 2007; Calvi and Mapelli, 2011).

Keywords: I need Spain, visual-verbal, conversational implicatures, language of tourism. 


\section{Introducción}

El turismo, en el sentido contemporáneo, no tiene orígenes remotos, ya que es gracias al abaratamiento de los costes del transporte aéreo que se transforma de actividad elitista con fines culturales, religiosos y formativos en actividad al alcance de muchos. El proceso se ha consolidado en las últimas décadas gracias también al nacimiento y a la afirmación de nuevas entidades (geo)políticas y a la difusión de las nuevas tecnologías que, con el turismo, han venido creando un vínculo muy estrecho (Mapelli, 2008; Mariottini, 2011). El siglo XX se puede, por eso, considerar el siglo en el cual se afirma el turismo moderno, un turismo pluridireccional tanto por la multiplicación de los destinos como por la variedad y versatilidad de los viajeros.

El incremento de destinos a nivel global y el contexto competitivo en el que se encuentran demandas y ofertas fuerzan a las empresas - y también a las instituciones públicas- a convertirse en "mercado orientado" (Ruddy / Flanagan, 2000) y a promocionar los destinos mediante campañas llamativas. En efecto, un factor clave, determinante para que un territorio tenga éxito dentro del sector del turismo, consiste en la creación y gestión de su imagen y en la manera en que esta se percibe (v., entre otros, Echtner / Richie, 2003). Los instrumentos alternativos proporcionados tanto por las tecnologías como por las posibilidades interactivas, multimodales ${ }^{1}$ (Kress / Van Leeuwen, 2001; La Mantia Massimino, 2011) permiten el entretenimiento y las representaciones auténticas, además de diseñar técnicas diferentes de comercialización, a través de las que se puede originar la imagen distintiva y atractiva que parece ser tan importante para que un país se posicione positivamente en la mente de los consumidores y para que se diferencie de los demás (para una revisión sobre el concepto y la importancia de la imagen del destino turístico, v. Giordana, 2004 y Chamizo Sánchez, 2003).

Según los datos del barómetro del turismo mundial para el año 2010, proporcionados por la Organización Mundial del Turismo, España es el cuarto destino turístico mundial, tras Estados Unidos, Francia y China (que superó a España justo ese año) y es también el primero del mundo en cuanto a repetición de visitas. El país dispone de un rico pasado en el turismo, que comenzó a florecer en la década de los sesenta y, si se exceptúa la década de los ochenta, cuando se percibió como una meta de mala calidad, del turismo de masa, cuya imagen fue dañada también por cuestiones ligadas al hacinamiento y al deterioro del medio ambiente, podemos afirmar rotundamente que España ha jugado y juega un papel de liderazgo en el turismo, demostrando, además, saber cambiar su imagen y ser activa y dinámica a la hora de adaptar sus campañas de marketing para hacer frente a los nuevos deseos del mercado. Todos estos aspectos hacen de España un país interesante a la hora de analizar las estrategias, las técnicas y los instrumentos lingüísticos empleados en una campaña de promoción turística (Calvi / Mapelli, 2011;
Liverani / Canals, 2011).

La comercialización de un destino turístico tiene como objetivo proponer una imagen que se ajuste a los deseos de los segmentos de mercado a los cuales se dirige ya que, como sostiene Krippendorf (1982), el turista va a un destino para ver la imagen en lugar de la realidad, es decir, que las percepciones que los consumidores tienen de un destino los motiva a actuar de forma independiente de la realidad. Por consiguiente, el desafío es crear algo atractivo y diferente (acordémonos de la antigua campaña de Turespaña, Spain is different) originando, además, el sentimiento de necesidad de fruición del servicio en los consumidores. En la presentación de la campaña online de Turespaña (2011) se dice, en efecto, que "los turistas que visitan España sienten la necesidad de volver", ellos son "adictos" y están "enganchados" a España. Por un lado, entonces, se construye la metáfora de España como una droga, que crea adicción y engancha, por el otro, se pone énfasis en el hecho de que "España se convierte en un destino turístico líder, único, global, aspiracional, experiencial y premium". He resaltado la palabra experiencial porque la campaña de Turespaña 2010 deslumbra los sentidos, el tacto, los corazones y estimula la mente del consumidor; responde plenamente a la definición que proporciona Levitt (1983), quien califica la publicidad como the poetry of becoming, ya que las personas buscan y aprecian no tanto lo que los productos o servicios les ofrecen funcionalmente, sino más bien lo que les prometen emocionalmente o les sugieren simbólicamente (v. también Pot, 2005).

El marketing del sector turístico tiene el propósito de alterar la imagen estándar de un país con el fin de acercarse cada vez más a la de la posición deseada por el consumidor. "La clave reside en crear aquel rasgo distintivo y llamativo de la imagen en la mente del turista y según su perspectiva" (Heath, 2000: 130), ya que los turistas contemporáneos queremos experimentar realidades de vida distintas, que sean interactivas y entretenidas y nos esperamos que las campañas "confundan los sentidos, hagan latir los corazones y estimulen las mentes" (Schmitt, 1999: 22). En otras palabras, ellas deben responder al modelo AIDA, acrónimo de Atención, Interés, Deseo, Acción: cuatro componentes esenciales para que las campañas resulten exitosas. Al aplicar el modelo AIDA al análisis de la campaña de Turespaña 2010, podemos rellenar el esquema como sigue:

- ATENCIÓN: La campaña es viva, elocuente, relajante, convincente, simple, emocionante, fascinante, joven, maravillosa, entusiasmante y llamativa. La atención está dirigida a las imágenes, a la presentación del ambiente natural y de la oferta cultural del país.

- INTERÉS: las frases negativas iniciales "no necesito" y la frase afirmativa final de cada anuncio (necesito España). El sol de Miró, logo de España con la frase "I need Spain".

- DESEO: el deseo se configura como la necesidad de ir a España o también como ganas de viajar y de evadir de la vida cotidiana”. 
- ACCIÓN: adhesión a los propósitos y a las emociones propuestas por el anuncio; identificación.

\section{Turespaña y la campaña 2010}

Los planes de actuación de Turespaña, así como se desprende de su página oficial, son "mantener y reforzar las campañas de imagen de la marca España con el fin de ampliar su reconocimiento y posición en el mercado turístico internacional", "desarrollar una estrategia de comunicación cuyo objetivo es resaltar los elementos esenciales y diferenciadores", "lograr una evolución de la imagen de España como destino turístico" y "obtener la mayor ventaja competitiva que se deriva de la existencia de una marca turística". Para alcanzar los objetivos mencionados, Turespaña actúa de forma conjunta con las Comunidades Autónomas mediante la realización de "campañas cooperativas que permiten asociar a la marca España los diferentes destinos y productos turísticos". Las campañas se trasmiten en los canales televisivos y por Internet, aparecen en los medios impresos y se promocionan a través de redes turísticas e institucionales. La campaña de Turespaña se ubica en una posición límite entre la publicidad comercial y la institucional, ya que en ella se promueven tanto bienes y servicios como la imagen de un país. Los propósitos son la presentación del patrimonio histórico, natural, cultural de España y, a la vez, la incitación a consumir la marca nacional. Las finalidades, corroboradas por la ley (Ley 29/2005 de Publicidad y Comunicación Institucional), coinciden también en parte con la caracterización propuesta por Dickason (2000), quien observa que los anuncios institucionales - entre otras cosas - crean sentimientos de identidad y empatía social, es decir, que este tipo de publicidad va más allá de lo instrumental y de lo funcional. El mensaje publicitario, de hecho, además del rol comercial que posee, representa también un importante instrumento de control social al proporcionarnos escalas de valores y modelos de conductas homogéneos con el fin de dirigir voluntades hacia el producto, el bien o el servicio, utilizando como canal preferencial el aspecto emocional de la audiencia y sus expectativas hedonísticas. El receptor ocupa un papel muy importante dentro del discurso publicitario de la campaña, ya que hacia él se dirige la comunicación para que actúe con la adhesión a la conducta promocionada.

A continuación, presento el contexto y texto verbal de la campaña, dejando al lector el gravamen de ir al enlace vídeo de la campaña de Turespaña 2010 (http://www.youtube.com; fecha de acceso 15 de febrero de 2012) ya que, por cuestiones editoriales, es imposible facilitar todos los cuadros (video frame) de las secuencias. En esta sede, en efecto, presentamos dos cuadros por cada situación que funcionen como ejemplos y que provean huellas del análisis conducido.

Primer anuncio:

Familias [voz femenina, habla una mujer joven, madre de tres hijos]

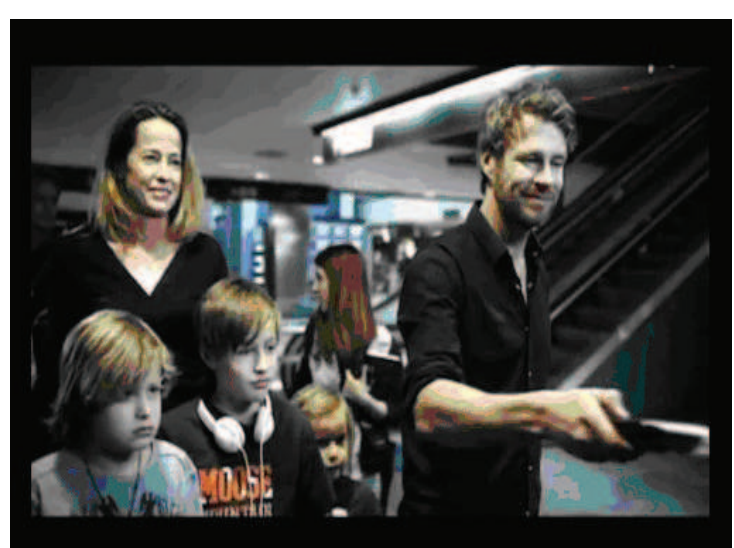

[en el aeropuerto] Cuantas menos cosas pongas en tu maleta más espacio queda para las vivencias.

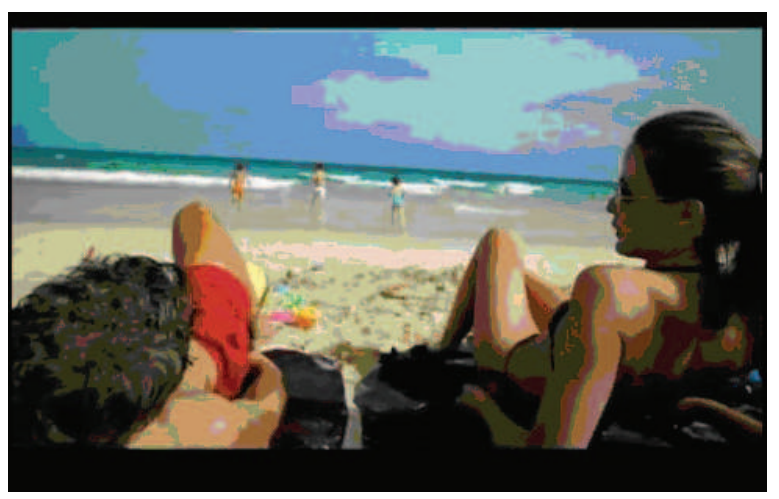

[en la playa] No necesito baby-sitter.

[en un restaurante, comiendo paella con langosta] No necesito fast necesito food.

[en un velero] No necesito tener los pies en la tierra. [en Valencia, palacio de las ciencias] No necesito palabras.

[en un sendero, hablando con dos habitantes ancianos] No necesito navegador.

[en un buffet libre] No necesito ver la carta.

Necesito que este viaje dure para siempre. Necesito España.

Segundo anuncio:

Jóvenes del mercado africano [voz masculina, habla un chico joven africano]

[en el aeropuerto] Amigo: la primera palabra que he aprendido en español.

[lanzándose a hacer surf] No necesito pensármelo dos veces. 


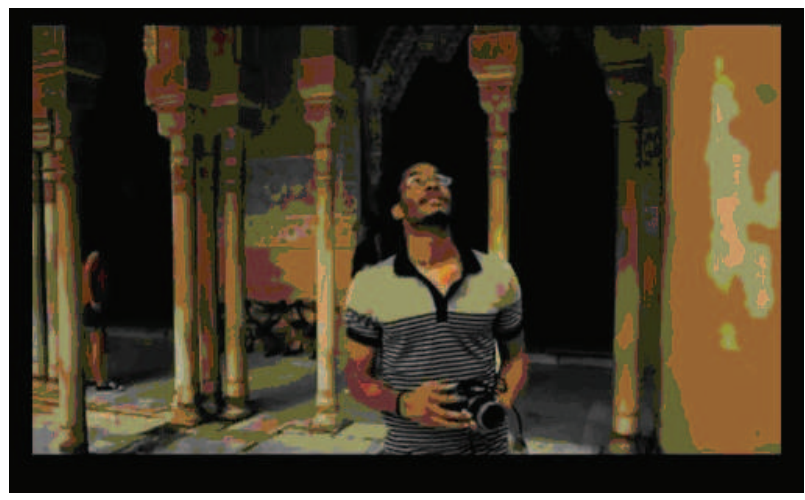

[en la Alhambra] No necesito que sea mío.

[en el estadio, viendo un partido de fútbol] No necesito televisión por cable.

[en un museo] No necesito entenderlo todo.

[en una discoteca] No necesito esperar al fin de semana.

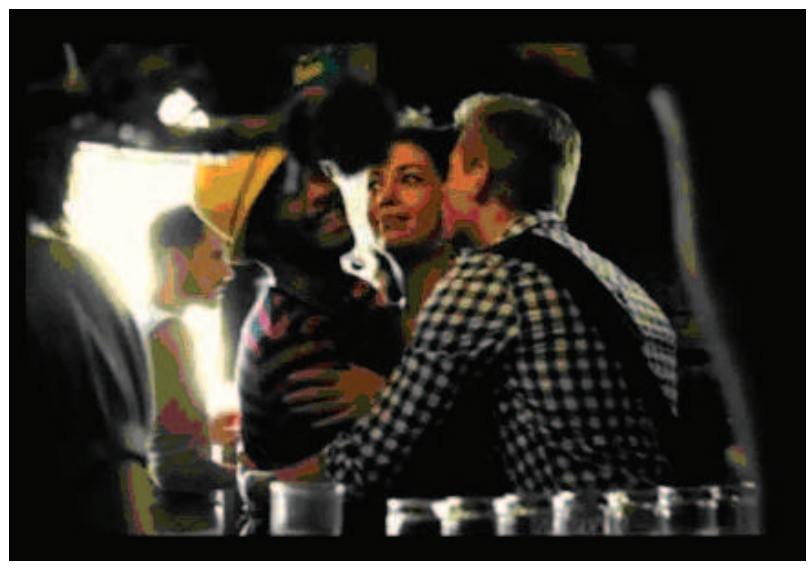

[en un bar, conociendo a gente nueva y hablando con unos amigos] No necesito el chat.

Necesito volver. Necesito España.

Tercer anuncio:

Mayores [habla un señor de edad avanzada]

[en el aeropuerto] Cuanto más viejo más sé lo que necesito.

[haciendo el camino de Santiago] No necesito ser el primero.

[en un baño árabe] No necesito tener un motivo.

[jugando al golf] No necesito ser un experto.

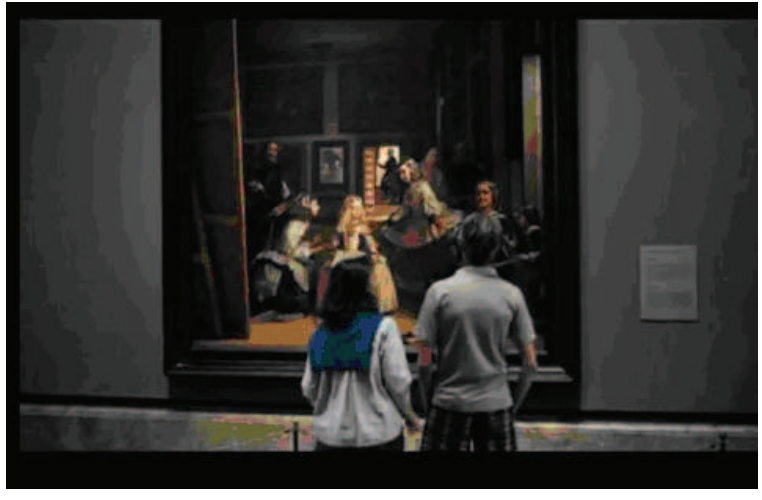

[en el Prado, viendo el cuadro de Las Meninas] No necesito postales.

[en un tablao flamenco] No necesito haber nacido aquí.

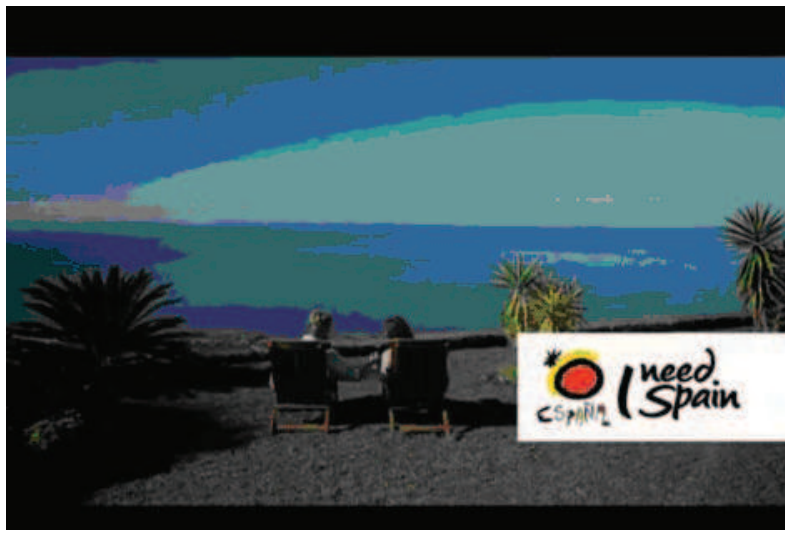

Necesito volver a darme cuenta de lo que es realmente importante. Necesito España.

\section{Cuarto anuncio:}

Asia [voz femenina, habla una chica de procedencia asiática]

[en el aeropuerto] A veces es necesario irse lejos para encontrarse con uno mismo.

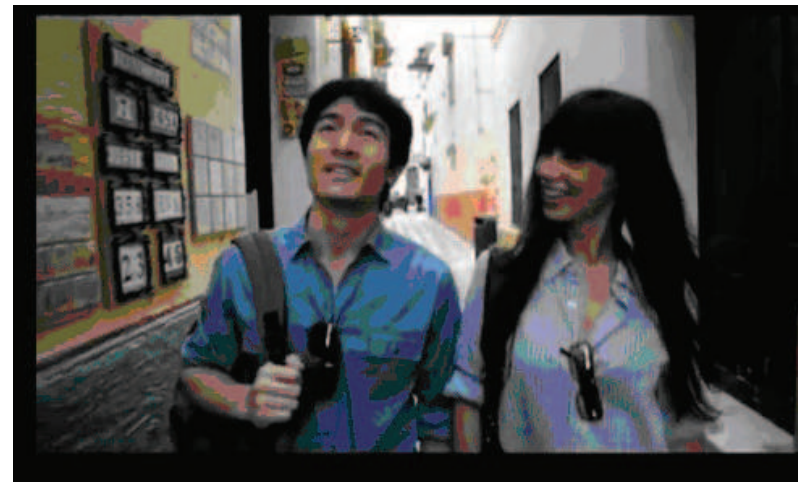


[en un restaurante panorámico] No necesito que me lo cuenten.

[en un mercado, comprando un reloj de pega] No necesito cuatro años de garantía.

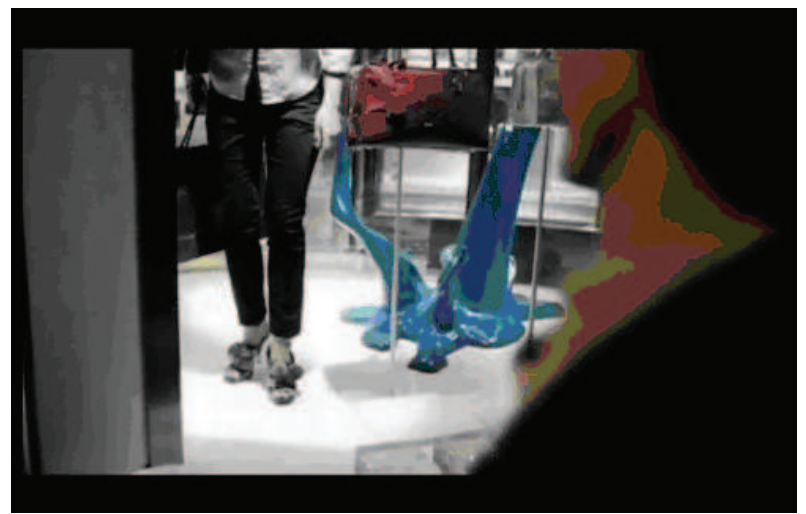

[en una zapatería] No necesito que me lo envuelvan. [admirando la Sagrada Familia] No necesito dormir para soñar.

[subiendo a la cumbre de una montaña] No necesito saber adónde voy.

Necesito que mi vida sea un viaje. Necesito España.

Los cuatro anuncios que componen la campaña presentan una frase de introducción al tema, leitmotiv del mensaje, y de presentación de los personajes (1. Cuantas menos cosas pongas en tu maleta más espacio queda para las vivencias; 2. Amigo: la primera palabra que he aprendido en español; 3. Cuanto más viejo, más sé lo que necesito; 4 . A veces es necesario irse lejos para encontrarse con uno mismo), después de la que empieza una serie de anáforas (no necesito) con las que se niegan necesidades (y porciones de mundo) que pertenecen al estereotipo del personaje representado ${ }^{2}$. Dichas negaciones se acompañan de imágenes que muestran por qué no se sienten tales necesidades. He subrayado muestran porque las imágenes son evidencias empíricas a partir de las que el destinatario debe contribuir a reconstruir y terminar el mensaje a través de un procedimiento implícito, inferencial, que integre los estímulos informativos - tanto verbales como visuales - recibidos. Al requerir la activación del procedimiento inferencial por parte del destinatario, el anuncio no solo está empleando estrategias de implicación pragmática del destinatario, sino que está exigiendo su colaboración activa para terminar el proceso de comunicación.

La necesidad del análisis pragmático para el lenguaje del turismo se evidencia, por lo tanto, en la medida en que ese ámbito emplea el lenguaje para informar e influir en sus destinatarios-clientes, a través de estrategias lingüísticas eficaces (según los destinatarios a quienes se dirige y según el contexto) para alcanzar una finalidad perlocutiva precisa (obtener el efecto de adhesión). Como decía también Ortega y Gasset (1956: 25) "las palabras no son palabras sino cuando son dichas por alguien a alguien [...] la realidad de la palabra es inseparable de quien la dice, de a quien va dicha y de la situación en que esto acontece". En efecto, la situacionalidad -condicio sine qua non de toda comunicación (De Beaugrande y Dressler, 1981)- ha de entenderse como lugar pragmático, es decir, contexto extralingüístico del mensaje, cuyos elementos principales son los participantes (emisor, destinatario), las coordenadas espacio-temporales de emisión, los actos de habla, las finalidades, las claves de interpretación del mensaje, los canales empleados para la comunicación y los géneros textuales y discursivos. Todos estos elementos están resumidos en el modelo SPEAKING propuesto por Hymes (1974) esquema que seguiré para el presente análisis, concentrándome en los aspectos que conciernen los participantes $(\mathrm{P})$, los actos de habla (A, con especial atención al implícito) y los instrumentos (I, combinación de lo visual con lo verbal) empleados para la comunicación.

\section{Análisis}

\section{El cuadro de participación: emisor-destinatario/yo-tú}

Para examinar el cuadro de participación, cabe precisar que hay dos niveles distintos de comunicación: el primero, externo a la campaña, que implica la institución y el público de posibles turistas-clientes; el segundo, interno a la campaña, vehiculado por los personajes que aparecen en los vídeos. Por lo tanto, hablaremos de emisor-destinatario en el primer caso, mientras que nos referiremos a la deíxis personal yo-tú en el segundo.

Primer nivel. Si nos adentramos en el macroacto comunicativo de la campaña de Turespaña, vemos que se trata de un encuentro comunicativo de grupo a grupo, puesto que los roles de hablante y destinatario no los ocupan personas concretas, sino dos colectivos: el emisor es un organismo institucional y el destinatario es un conjunto de personas. Sin embargo (v. Hernández Flores, 2010), hay dos perspectivas distintas; por una parte, la de la emisión, en la que la realización de la actividad comunicativa procede de un grupo - la institución anunciadora Turespaña - que no funciona como un conjunto de individuos, sino de manera compacta, única e impersonal, que se dirige a otro grupo - el de los ciudadanos españoles o extranjeros, turistas potenciales - igualmente compacto, único e impersonal, de forma que su mensaje se adecuará a las características comunes atribuidas a los grupos destinatarios (que en este caso son cuatro, es decir, las familias, los jóvenes del mercado africano, los jóvenes del mercado asiático y los mayores). Pero, por otra parte, el mensaje puede tener distintos efectos porque el grupo receptor deja de funcionar como grupo, siendo el receptor cada individuo de esa colectividad; de ahí que, cada uno de ellos puede tener una distinta interpretación del mensaje y, por tanto, distinta actitud hacia él. De hecho, en publicidad, lo único que une al grupo es el de compartir interés o estar influidos por algo relacionado con el producto o servicio publicitado y, también, compartir algunos rasgos de identificación social pero todo eso no implica la exist- 
encia de una "conciencia de grupo" (Kaul de Marlangeon, 2006). Las reacciones de los individuos destinatarios, por lo tanto, pueden ser diferentes: algunos se identificarán, otros no, otros reaccionarán con indiferencia y otros más se sentirán racional o emotivamente comprometidos.

Segundo nivel. Los estudios llevados a cabo en el ámbito del proyecto de investigación "Il linguaggio della comunicazione turistica spagnolo-italiano. Aspetti lessicali, pragmatici e interculturali (PRIN 2007, prot. 2007 ASKNML), coordinado por M.V. Calvi, han examinado los géneros textuales y discursivos de este ámbito de especialidad, subrayando, entre otros aspectos, las estrategias lingüísticas de implicación del destinatario (v., entre otros, Calvi, 2009; Calvi / Mapelli, 2011; Liverani / Canals, 2011; Ares Ares, 2011).

Calvi (2009: 210) afirma a este propósito que "la naturaleza persuasiva del discurso turístico hace que abunden los recursos de implicación del interlocutor, tanto en el plano lingüístico (morfosintaxis y léxico) como a nivel gráfico e icónico [...]" y que "las apelaciones directas son propias de los textos publicitarios y promocionales [...] la segunda persona se combina a menudo con el imperativo y otras formas exhortativas, pronombres personales, posesivos, etc. [...] Otro recurso cada vez más corriente en todo tipo de texto turístico es el nosotros participativo, es decir una primera persona del plural que aúna emisor e interlocutor, sugiriendo una forma de complicidad".

Ahora bien, en el texto de la campaña de Turespaña 2010, nos enfrentamos a un uso de la deíxis personal peculiar para los fines de inclusión del destinatario arriba mencionados, ya que la única persona verbal que aparece es la primera del singular (yo), presente en las formas flexivas del verbo anafórico "no necesito". Realmente, no podemos hablar más que de un procedimiento indirecto de implicación. Los verbos en la primera persona hacen que se establezca una relación polar (identificación-oposición) entre el yo hablante y el tú destinatario del mensaje. Es decir, aunque no se diga “¿y tú qué necesitas?” o “¿y tú necesitas España?", sí se hace implícitamente. Se trata, pues, de una estructura focalizadora implícita que tiene un fin comunicativo (Alcaide Lara, 2010): contraponer una persona del discurso a otra, en este caso, claramente, yo a tú. Por lo tanto, estamos ante un caso de persuasión desarrollada a través de procedimientos indirectos, que son los que activarán la necesidad y el deseo del destinatario de adherir a la imagen propuesta y de trasladarse a la situación presentada.

\section{Los instrumentos}

La campaña de Turespaña 2010 no presenta solo texto verbal, sino también texto visual (v. también Czerpa, 2006); es decir, explota todo recurso semiótico que las posibilidades mediáticas hodiernas ponen a su disposición $y$, por consiguiente, construye una textualidad en la que reina la combinación de distintos canales, distintos códigos en el mensaje (codificación sincrética y aglutinante; v. López Eire, 2003: 48; o también codificación multimodal), eficazmente entremezclados al fin de obtener los efectos promocionales esperados (Held, 2007).

La presentación multimodal del mensaje es una estrategia excelente para argumentar y persuadir porque que se basa en las distintas formas de representar de las dimensiones verbal y visual: lo verbal consta de lenguaje asertivo y su forma de representar acontecimientos es lógica (principio de cooperación e inferencias, por ejemplo), en cambio lo visual emplea una forma de comunicar empírica y emocional.

En el caso específico de análisis, la relación que se establece entre lo visual y lo verbal es de tipo complementario, ya que la interacción entre texto e imagen es el elemento activador del procedimiento inferencial (para una revisión sobre las inferencias originadas de la combinación entre texto visual y verbal, v. también Smith, 1991). Es gracias a las imágenes que el destinatario se da cuenta de que lo dicho discrepa de lo comunicado (lo que se dice literalmente y lo que realmente se quiere decir), como explicaré en el siguiente apartado.

\section{Los actos de habla: el implícito y la inferencia}

Un recurso pragmático de implicación del destinatario, muy utilizado en los textos promocionales y publicitarios (pero no muy estudiado en ellos; v. Lombardi Vallauri, 2009), es el de la implicatura conversacional (Grice, 1975). Parafraseando a Grice, la implicatura es una inferencia necesaria para lograr la comprensión de los significados que se activa cuando se violan las máximas del Principio de cooperación. De ahí que, si el hablante no contribuye a la conversación con un suficiente grado de cooperación, el destinatario suplirá a esta violación infiriendo la información que falta para que la contribución siga resultando informativa/verdadera/adecuada/clara. Al hacer eso, el destinatario llega a desempeñar el papel de coautor, fuente enunciadora aliada del emisor, ya que, con sus implicaturas, contribuye a terminar el proceso de enunciación. De ahí que la concepción convencional (Sbisà, 1994) de los enunciados deja lugar a una visión interaccional, "transcontextual y transindividual" (Orletti, 1994: 16) en la que no se pone énfasis en la mera transmisión de fines ilocutorios, sino más bien en la compleja labor interpretativa de los participantes en la comunicación. Esta perspectiva pragmática arroja luz sobre el papel del destinatario, sobre las acciones inferenciales que este activa a partir de las condiciones interpretativas que le ofrece el contexto y a partir de los elementos situacionales que las orientan, además de dar explicación sobre las consecuencias psicológicas y emocionales de los eventos comunicativos.

A continuación presento unas posibles implicaturas originadas de la interacción entre lo verbal y lo visual.

Primer anuncio:

Familias

Cuantas menos cosas pongas en tu maleta más espacio queda para las vivencias.

No necesito baby-sitter [en las playas españolas estoy tranquila]

No necesito fast necesito food [necesito comida genuina] 
No necesito tener los pies en la tierra [cuando/porque navego]

No necesito palabras [mirar me es suficiente]

No necesito navegador [pido informaciones a las personas que viven allí]

No necesito ver la carta [puedo elegir entre un rico buffet]

Necesito que este viaje dure para siempre. Necesito España.

Segundo anuncio:

Jóvenes del mercado africano.

Amigo: la primera palabra que he aprendido en español.

No necesito pensármelo dos veces [me lanzo a una nueva aventura]

No necesito que sea mío [lo visito y disfruto de su belleza]

No necesito televisión por cable [veo el partido en directo en el estadio]

No necesito entenderlo todo [aprecio el arte]

No necesito esperar al fin de semana [en todo momento puedo hacer algo especial y divertido con mis amigos]

No necesito el chat [hablo y me "conecto" con mis amigos, conozco a gente nueva]

Necesito volver. Necesito España.

Tercer anuncio:

Mayores

Cuanto más viejo más sé lo que necesito.

No necesito ser el primero [disfruto del camino de Santiago]

No necesito tener un motivo [me dedico a mí mismo]

No necesito ser un experto [juego al golf]

No necesito postales [voy al museo]

No necesito haber nacido aquí [veo, entiendo y me emociono con el flamenco]

Necesito volver a darme cuenta de lo que es realmente importante. Necesito España.

Cuarto anuncio:

Asia

A veces es necesario irse lejos para encontrarse con uno mismo.

No necesito un taxi [vamos callejeando]

No necesito que me lo cuenten [lo vivo en primera persona]

No necesito cuatro años de garantía [es un símbolo y un recuerdo de un momento especial]

No necesito que me lo envuelvan [salgo de la tienda con los zapatos puestos]

No necesito dormir para soñar [la Sagrada Familia es un sueño]

No necesito saber adónde voy [descubriré un paisaje maravilloso]

Necesito que mi vida sea un viaje. Necesito España.

Además de activar el procedimiento inferencial, las imágenes, dado que son las que mueven emociones, hacen que el destinatario no sea solo coautor, sino también coexperimentador (contribuya a construir y perciba las mismas sensaciones y sentimientos de los personajes repre- sentados en los anuncios).

\section{Conclusiones}

En el presente artículo he desarrollado un análisis lingüístico, desde la perspectiva pragmática, de la campaña de promoción turística de Turespaña 2010 I need Spain.

El propósito de mi contribución era destacar el papel que desempeña la lengua en el ámbito de la promoción turística, ya que los estudios aparecidos en estos últimos 30 años proceden, sobre todo, de los ámbitos sociológico, psicológico, semiológico y de mercado. En mi trabajo de investigación, me he centrado en el análisis de las estrategias pragmáticas de comunicación y los efectos que ellas ejercen en los destinatarios. La estrategia empleada a lo largo de los cuatro anuncios que componen la campaña es la implicatura conversacional, es decir, la activación por parte del destinatario de un procedimiento inferencial a partir de la interacción entre la información visual y verbal proporcionada (codificación multimodal del mensaje). La implicatura conversacional tiene doble función y ventaja: la primera (que destaca también Lombardi Vallauri, 2009) es la de no presentar las informaciones como conclusiones aseverativas, sino más bien de trasladar esas últimas a la dimensión de lo implícito; la segunda es la de implicar activamente al destinatario, en la medida en que le deja la tarea de terminar la comunicación. Al hacer eso, el destinatario llega a ser aliado del emisor, coautor y, por tanto, corresponsable del mensaje. Sin embargo, el papel de las imágenes no se limita a vehicular información implícita, sino que abarca también la comunicación emocional, ya que las imágenes de la campaña suscitan emociones en el público receptor. Desde la perspectiva de la lingüística pragmática, esto quiere decir que el destinatario juega un papel doblemente activo. Por una parte, es coautor del mensaje (lenguaje verbal, representación lógica de los acontecimientos), por otra parte, él se configura también como coexperimentador, es decir, como una entidad que forma parte emocionalmente del anuncio, ya que contribuye a construir y percibe las sensaciones, emociones y los sentimientos de los personajes representados (lenguaje visual, representación empírica y emocional de los acontecimientos).

\section{Bibliografía}

\section{Alcaide Lara, Esperanza}

2010 "La descortesía (también) "vende": acercamiento al estudio de estrategias descorteses en el discurso publicitario". En Orletti, Franca / Mariottini, Laura (Eds.), (Des)cortesía en español: espacios teóricos y metodológicos para su estudio (pp. 221-244). Romal Stockholm: Università Roma Tre/Programa EDICE.

Aragón Cobo, Marina / Eurrutia Cavero, Mercedes / Planelles Ibáñez, Montserrat

2007 "El lenguaje del turismo". En Alcaraz Varó, Enrique / Mateo Martínez, José / Yus Ramos, Francisco (Eds.), 
Las lenguas profesionales y académicas (233-245). Barcelona: Ariel.

Ares Ares, Álida

2011 "Deíxis y procedimiento de modalización en reportajes de viaje". En Liverani, Elena / Canals, Jordi (Eds.), El discurso del turismo. Aspectos lingüisticos y variedades textuales (163-198). Trento: Tangram Edizioni.

Calvi, Maria Vittoria

2009 "El lenguaje del turismo". En Calvi, Maria Vittoria / Bordonaba Zabalza, Cristina / Mapelli, Giovanna / Santos López, Javier (Eds.), Las lenguas de especialidad en español (pp. 199-224). Roma: Carocci.

Calvi, Maria Vittoria / Mapelli, Giovanna (Eds.)

2011 La lengua del turismo. Géneros discursivos y terminología. Bern: Peter Lang.

Chamizo Sánchez, Rocío

2003 Introducción a la comunicación turística. Málaga: Universidad de Málaga.

Czerpa, Dorota

2006 "Language and image. A comparative study of advertisements in English and Swedish magazines for adult women and teenage girls". LIMS, 9. En http:// epubl.luth.se/1402-1552/2006/080/index.html [fecha de acceso: 20 de octubre de 2011]

De Beaugrande, Robert A. y Dressler, Wolfang U.

1981 Introduction to text linguistics. London: Longman.

Dickason, Renee

2000 British Television Advertising. Cultural Identity and Communication. Luton: University of Luton Press.

Echtner, Charlotte / Ritchie, Brent

2003 "The Meaning and Measurement of Destination Image". The journal of tourism studies, 14(1): pp. 37-46.

Escandell, María Victoria

1994 Introducción a la Pragmática. Madrid: Taurus.

Giordana Francesco

2004 La comunicazione del turismo tra immagine, immaginario e immaginazione. Milano: FrancoAngeli.

Grice, Paul

1975 "Logic and Conversation". En Cole, Peter y Morgan, Jerry (Eds.), Syntax and Semantics, 3: Speech Acts (pp. 43-58). New York: Academic Press.

Heath, Ernie

2000. Key Trends and challenges in destination marketing: the need for a new paradigm. En Ruddy, Joseph / Flanagan, Sheila (Eds.), Tourism Destination Marketing; Gaining the Competitive Edge (pp. 123-135). Dublin: Tourism Research Centre, Dublin Institute of Technology.

Held, Gudrun

2004 "L'annuncio pubblicitario di destinazione. Osservazioni su un tipo di testo multimodale nella stampa odierna". En D'Achille, Paolo (Ed.), Generi, architetture e forme testuali (pp. 257-277). Firenze: Cesati.

Held, Gudrun

2005 "A proposito di una nuova testualità. Osservazioni semiotiche e linguistiche in base ai testi multimodali della stampa odierna”. Italienisch, 54: 46-63.
Held, Gudrun

2007 "Spazi, segni e sogni: l'annuncio di destinazione, testo multimodale nella comunicazione turistica". En Santulli, Francesca / Antelmi, Donatella / Held, Gudrun (Eds.), Pragmatica della comunicazione turistica (221-285). Roma: Editori Riuniti University Press.

Hernández Flores, Nieves

2010 "Actividades de imagen en la publicidad institucional española: la confianza social en el sistema". En Orletti, Franca / Mariottini, Laura (Eds.), (Des)cortesía en español: espacios teóricos y metodológicos para su estudio (pp. 261-283). Roma/Stockholm: Università Roma Tre/Programa EDICE.

Hymes, Dell

1974 Foundations in Sociolinguistics: An Ethnographic Approach. Philadelphia: University of Pennsylvania Press.

Kaul de Marlangeon, Silvia

2006 "El género horóscopo. Cortesía e ideología". En Blas Arroyo, José Luis et al. (Eds.), Discurso y sociedad: contribuciones al estudio de la lengua en contexto social (pp. 649-659). Castellón: Universitat Jaume I.

Kress, Gunter / Van Leeuwen, Theo

2001 Multimodal Discourse. The Modes and Media of Contemporary Communication. London: Arnold.

Krippendorf, Jost

1982 "Towards new tourism policies: The importance of environmental and sociocultural factors". Tourism Management, septiembre: pp. 135-48.

La Mantia Massimino M. Lynne

2011 "Multimodal Discourse in Advertising: Student Analysis of Print Ads using Recognized Advertising Concepts". En Maruenda-Bataller, Sergio / Claver-Arroitia, Begoña (Eds.), Multiple Voices in Academic and Professional Discourse: Current Issues in Specialized Language Research, Teaching and New Technologies (102-112). Cambridge: Cambridge Scholars Publishing.

Levitt, Theodore

1983 The Marketing Imagination. New York: Free Press. Ley 29/2005 de Publicidad y Comunicación Institucional 2005 Boletín Oficial del Estado n. 312 (30/12/2005). Madrid: Ministerio de la Presidencia. http://www.boe.es/ boe/dias/2005/12/30/pdfs/A42902-42905.pdf [Fecha de consulta: 20 de octubre de 2011]

Liverani, Elena / Canals, Jordi (Eds.)

2011 El discurso del turismo. Aspectos lingüísticos y variedades textuales. Trento: Tangram Edizioni Scientifiche.

Lombardi Vallauri, Edoardo

2009 "Grice elettorale". En Fatigante, Marilena, Mariottini, Laura / Sciubba, M. Eleonora (Eds.), Lingua e società. Scritti in onore di Franca Orletti (pp. 172-184). Roma: FrancoAngeli.

López Eire, Antonio

2003 La retórica en la publicidad. Madrid: Arco/Libros.

Mapelli, Giovanna

2008 "Las marcas de metadiscurso interpersonal de la 
sección 'turismo' de los sitios web de los ayuntamientos". En Calvi, Maria Vittoria / Mapelli, Giovanna / Santos López, Javier (Eds.), Lingua, culture, economia. Comunicazione e pratiche discorsive (pp. 173189). Milano: FrancoAngeli.

Mariottini, Laura

2011 "El lenguaje jurídico y las Nuevas Tecnologías: análisis de los blogs de abogados". En Clavel, Begoña, Maruenda, Sergio (Eds.), Multiple Voices in Academic and Professional Discourse: Current Issues in Specialised Language Research, Teaching and New Technologies (pp 187-198). Cambridge: Cambridge Scholar Publishing.

Orletti, Franca

1994 (Eds.), Fra conversazione e discorso. Roma: Carocci.

Ortega y Gasset, José

1956 "El decir de la gente: La lengua hacia una nueva lingüística". La Torre, 15/16: 15-42.

Pot, Claire

2005 An evaluation of Spain's marketing campaign 'Smile you are in Spain', through an image analysis in the Dutch market. Bournemouth: Bournemouth University.

Ruddy, Joseph / Flanagan, Sheila

2000 (Eds.), Tourism Destination Marketing; Gaining the Competitive Edge. Dublin: Tourism Research Centre, Dublin Institute of Technology.

Santulli, Francesca / Antelmi, Donatella / Held, Gudrun 2007 Pragmatica della comunicazione turistica. Roma: Editori Riuniti University Press.

Sbisà, Marina

1994 "Per una pragmatica degli atti linguistici: quasi un bilancio". En Orletti, Franca (Ed.), Fra conversazione e discorso (pp. 29-47). Roma: Carocci.

Schmitt, Bernd $\mathrm{H}$.

1999 Experiential Marketing; How to get customers to sense-feel-think-act-relate to your company and brands. New York: Free Press.

Smith, Ruth A.

1991 "The effects of visual and verbal advertising information on consumers' inferences". Journal of advertising, 20: 13-24.

Vilarnovo, Antonio / Sánchez, José Francisco

1992 Discurso, Tipo de texto y comunicación. Pamplona: EUNSA.

\section{Notas}

1 Con el término multimodalidad entiendo los múltiples canales - verbal, visual, emocional, sensorial - en los que se realiza el evento comunicativo.

2 Vilarnovo y Sánchez (1992) afirman que en la publicidad los personajes que se representan no son verdaderos caracteres, sino que son estereotipos, modelos reconocibles socialmente, clichés establecidos que actúan según lo que cabe esperar de ellos por un prejuicio social. Para el publicista tanto el personaje que vemos representado en el anuncio como el receptor al que va dirigido el mismo son modelos, son realmente conjuntos de topoi.

Recibido:

$29 / 12 / 2011$

Reenviado:

$6 / 3 / 2012$

Aceptado:

$18 / 3 / 2012$

Sometido a evaluación por pares anónimos 